\title{
Relationship Between Asymmetric Dimethylarginine (ADMA) and Atherosclerosis in Chronic Renal Failure Patients
}

\author{
Alsayed Rashed ${ }^{1}$, Kamel Soliman ${ }^{1}$, Abdelaziz Aun ${ }^{1}$ and Haitham Ezzat ${ }^{2 *}$ \\ ${ }^{1}$ Nephrology Department, Alazhar University, Cairo Governorate, Egypt \\ 2 Nephrology Department, Ain Shams University, Cairo Governorate, Egypt
}

"Corresponding author: Haitham Ezzat, Nephrology Department, Ain Shams University, Khalifa El-Maamon St El-Qobba Bridge, Cairo Governorate 11566, Egypt, Tel: +201006499550; E-mail: haitham_ezzat@hotmail.com

Received Date: July 26, 2017; Accepted Date: August 02, 2017; Published Date: August 09, 2017

Copyright: (c) 2017 Ezzat H, et al. This is an open-access article distributed under the terms of the Creative Commons Attribution License, which permits unrestricted use, distribution, and reproduction in any medium, provided the original author and source are credited.

\begin{abstract}
Background: Serum ADMA level was high in hemodialysis patients as compared to healthy control population. Increase in ADMA levels may play a role in atherosclerosis dependent morbidity and mortality.
\end{abstract}

Objective: Assessment of the relationship between serum ADMA and atherosclerosis.

Patient and methods: Serum ADMA was measured using ADMA ELISA Kit; atherosclerosis was assessed by non- invasive methods including FMD and CIMT in 3 groups (50 ESRD patients undergoing hemodialysis, 25 CKD patients stage IV and 25 healthy control subjects).

Results: CKD and ESRD patients on regular haemodialysis have significantly greater ADMA, CIMT and lesser FMD than do control subjects with normal renal function. Both groups of patients have higher cholesterol and triglycerides levels than do control subjects which could be related to serum ADMA. Serum albumin was reduced in haemodialysis and CKD patients; it has an inverse correlation with serum ADMA.

Conclusion: Patients of CKD and haemodialysis have earlier endothelial dysfunction than do control group and this explains why they have higher incidence of cardiovascular morbidity and mortality. Integration of ADMA into currently applied risk scores still needs to be validated.

Keywords: Dimethylarginine; Haemodialysis; Brachial artery; Endothelium

\section{Introduction}

Asymmetric dimethylarginine (ADMA) is an analog of L-arginine that inhibits in vivo nitric oxide (NO) synthesis by competing with Larginine at the active site of NO synthase (NOS). NO is a potent vasodilator that plays a critical role in maintaining vascular homeostasis through its anti-atherogenic and anti-proliferative effects on the vascular wall [1]. ADMA is associated with endothelial dysfunction [2].

Serum ADMA level was high in hemodialysis patients as compared to healthy control population which may play a role in atherosclerosis dependent morbidity and mortality [3]. In chronic kidney disease, ADMA is an independent marker of progression of renal disease, vascular complications and mortality [4].

Plasma ADMA is an important biochemical marker of micro vascular disease progression in the kidney and might play an important role in the development of end organ damage in essential hypertension [5].

Serum ADMA was related reversely to flow mediated dilation (FMD) of brachial artery. In multiple regression analysis, ADMA was the only independent determinant of FMD [6].
There is a strong relationship between ADMA and FMD in hypercholesterolemia. ADMA is the basic modulator of \%FMD among all tested atherogenic risk biomarkers in severe hypercholesterolemia [7].

Traditional risk factors such as plasma cholesterol and triglycerides levels were significantly associated with asymptomatic carotid atherosclerosis. High serum concentrations of ADMA were associated with carotid atherosclerotic lesions as measured by carotid intimal media thickness (CIMT) and may represent a new non-traditional marker of asymptomatic carotid atherosclerosis [8].

Cardiovascular disease due to atherosclerosis is the leading cause of death in patients with chronic kidney failure. Patients with chronic kidney disease exhibit evidences of early and exaggerated vascular and cardiac remodeling, i.e., arteriosclerosis and left ventricular hypertrophy [9]. Cardiac non-traditional risk factors specific to chronic kidney failure as volume overload, hyper- parathyroidism, uremia, anemia and endothelial dysfunction may also play a role in the process of atherosclerosis [10].

The aim of this study was to assess serum ADMA levels and their relationship to endothelial dysfunction, carotid intima-media thickness (CIMT) and brachial artery flow mediated dilation (FMD) in chronic renal failure (CRF) patients on conservative treatment as well as hemodialysis (HD) patients. 


\section{Patient and Methods}

This study included100 subjects; they were divided into three groups:

Group 1: This group included $50 \mathrm{CRF}$ patients who underwent regular hemodialysis (HD) three times weekly, each dialysis session were performed in 3 hours. Blood access was through arteriovenous fistula (AVF). The duration of hemodialysis ranged between 29 and 100 months with a mean of $58.38 \pm 19.83$ months. Their age ranged between 19 and 81 years with a mean of $45.8 \pm 13.7$ years. 31 of them were males and 19 were females.

Group 2: This group included $25 \mathrm{CKD}$ patients on conservative treatment (stage 4). Their creatinine clearance ranged from 15.12 to 28 $\mathrm{ml} / \mathrm{min}$ with a mean of $20.34 \pm 3.8 \mathrm{ml} / \mathrm{min}$. Creatinine clearance was calculated by the Cockcroft-Gault formula. For men, the formula was $(140$-age $) \times($ weight in $\mathrm{kg}) / 72 \times$ serum creatinine. For women, this result was multiplied by the factor 0.85 [11]. They were 13 males and 12 females. The age of this group ranged between 29 and 75 years, with a mean of $48.6 \pm 12.9$ years.

Group 3: This group included 25 normal healthy subjects used as controls. 13 of them were males and 12 were females. Their ages ranged between 25 and 75 years, with a mean of $47.4 \pm 14.06$ years.

\section{Exclusion criteria}

1. CKD stage 1.2.3.

2. Irregular hemodialysis patients.

3. Symptomatic carotid artery disease (CAD) that necessitated revascularization therapy or recent endovascular interventions.

\section{Collected data from all groups included}

1. Full medical history (familial diseases, concomitant diseases, pharmacotherapy used, and smoking).

2. Physical examination including blood pressure measurement, heart, chest and abdomen examination and body weight.

3. Lab Investigations: $\mathrm{CBC}$, blood urea nitrogen (BUN), serum creatinine, serum albumin, estimated glomerular filtration rate (GFR) in stage $4 \mathrm{CKD}$ group, serum cholesterol and serum triglycerides.

The serum ADMA concentration was assessed by the ADMA ELISA kit (Bio Assay Technology Laboratory, 2016) [12]. Serum samples were collected from patients prior to dialysis and then samples were allowed to clot for 10-20 minutes at room temperature. Samples were centrifuged and stored at -20 temperatures. The test was based on binding of ADMA from samples to coated antibody on the microwells, bound ADMA was detected by horseradish peroxidase (HRP) labled detection antibodies. Assay range of the test was $2 \mathrm{ng} / \mathrm{ml}$ to $600 \mathrm{ng} / \mathrm{ml}$. Sensitivity of the test was $1.21 \mathrm{ng} / \mathrm{ml}$.

Assessment of flow-mediated vasodilatation (FMD) of brachial artery according to the American College of Cardiology guidelines [13]. The brachial artery was scanned $5-15 \mathrm{~cm}$ above the antecubital fossa. Resting diameter was measured, and then a blood pressure cuff was inflated around the arm to at least $50 \mathrm{mmHg}$ above SBP for 4.5 minutes. A measurement of maximum diameter was taken $45-60$ seconds after cuff release. Distance was measured from the anterior to the posterior $\mathrm{M}$ lines (media-adventitia interface). USG machine with high resolution (B) scan $7.5 \mathrm{~Hz}$ linear accelerator was used to assess brachial artery diameter and its changes.
FMD $=[$ (post-deflation diameter- resting diameter $) /$ resting diameter $] \times 100$

Assessment of intima-media thickness (IMT) of carotid arteries. Common carotid artery (CCA) was measured by high-resolution Bmode ultrasonography with a $7.5-\mathrm{MHz}$ transducer. Measurements of CCA diameter and CCA-IMT were always performed opposite to the side of atrioventricular shunts $2 \mathrm{~cm}$ beneath the bifurcation. Measurements of CCA-IMT were done on the far wall at the same level as the diameter measurements.

\section{Statistical methods}

The data were entered, coded and processed on computer using Statistical Packaged for Social Science [14]. The level P $\leq 0.05$ was considered the cut-off value for significance. Tests used in the study were [Chi-Square test $\chi^{2}$, Fisher exact test, one way ANOVA, Post Hoc Tests (mean difference and $\mathrm{P}$ value), Pearson correlation for quantitative variables, and ROC curve was used to test Sensitivity and specificity of quantitative variable].

\section{Results}

Cross sectional study was applied on 50 hemodialysis patients, 25 CKD stage 4 patients and 25 healthy control subjects. Sample size was calculated using sample size calculator with confidence level of $95 \%$ and margin of error of $5 \%$ in population 93.

There was a statistical significant difference between the three groups regarding the mean of weight with higher body weight of control group than patient groups. However there was no statistical significant difference between the three groups regarding the age and sex with a higher percentage of male than female in all studied groups (Table 1).

\begin{tabular}{|c|c|c|c|c|}
\hline \multirow[t]{2}{*}{$\begin{array}{l}\text { Group } \\
\text { Parameter }\end{array}$} & $\begin{array}{l}\text { Group } 1 \\
\text { CRF }\end{array}$ & $\begin{array}{l}\text { Group } 2 \\
\text { CKD }\end{array}$ & $\begin{array}{l}\text { Group } 3 \\
\text { Control }\end{array}$ & \multirow[t]{2}{*}{ Pvalue } \\
\hline & \multicolumn{3}{|c|}{ Mean \pm SD } & \\
\hline Age (yr) & $45.8 \pm 13.7$ & $48.6 \pm 12.9$ & $47.4 \pm 14.06$ & $>.050$ \\
\hline \multirow[t]{2}{*}{ Weight (kg) } & $74.8 \pm 8.07$ & $72.4 \pm 7.8$ & $78.5 \pm 10.7$ & $<0.050^{*}$ \\
\hline & \multicolumn{3}{|l|}{$\mathrm{n}(\%)$} & $P$ value \\
\hline Sex-Male & $31(62)$ & $13(52)$ & $13(52)$ & \multirow[t]{2}{*}{$>0.050$} \\
\hline Female & $19(38)$ & $12(48)$ & $12(48)$ & \\
\hline
\end{tabular}

ANOVA: Analysis of variance; $\mathrm{x} 2$ : Chi-Square; SD: Standard deviation; CRF: Chronic renalfailure; CKD: Chronic kidney disease

Table 1: Descriptive data of studied groups.

There was a statistical significant difference between the three groups regarding the mean of ADMA, IMT and FMD, with a higher mean of ADMA and IMT in patients groups than control group. However there was a higher mean of FMD in control group than patients groups (Table 2).

There was a statistical significant difference between the three groups regarding the mean of creatinine, hemoglobin, albumin, cholesterol and triglyceride. There was a higher mean of creatinine, cholesterol and triglycerides in hemodialysis and CKD 4 groups than in control group. However, there was a lower mean of hemoglobin, 
Citation: Rashed A, Soliman K, Aun A, Ezzat H (2017) Relationship Between Asymmetric Dimethylarginine (ADMA) and Atherosclerosis in

Page 3 of 5

albumin in hemodialysis and CKD 4 groups than in control group (Table 3).

\begin{tabular}{|c|c|c|c|c|c|}
\hline \multirow[t]{2}{*}{$\begin{array}{l}\text { Group } \\
\text { Parameter }\end{array}$} & $\begin{array}{l}\text { Group } 1 \\
\text { CRF }\end{array}$ & $\begin{array}{l}\text { Group } 2 \\
\text { CKD }\end{array}$ & $\begin{array}{l}\text { Group } 3 \\
\text { Control }\end{array}$ & \multirow[t]{2}{*}{$\begin{array}{l}\text { ANOV } \\
\text { A }\end{array}$} & \multirow[t]{2}{*}{ P-value } \\
\hline & \multicolumn{3}{|c|}{ Mean \pm SD } & & \\
\hline ADMA ( $\mathrm{ng} / \mathrm{ml})$ & $\begin{array}{l}39.64 \quad \pm \\
9.2\end{array}$ & $\begin{array}{ll}35.03 & \pm \\
8.39 & \end{array}$ & $\begin{array}{l}20.93 \quad \pm \\
2.17\end{array}$ & 47.482 & $<0.001^{* *}$ \\
\hline $\mathrm{IMT}(\mathrm{mm})$ & $\begin{array}{l}0.86 \quad \pm \\
0.13\end{array}$ & $0.87 \pm 0.13$ & $0.48 \pm 0.08$ & 86.448 & $<0.001^{* *}$ \\
\hline FMD\% & $\begin{array}{l}6.02 \\
1.73\end{array}$ & $5.98 \pm 1.85$ & $\begin{array}{l}17.62 \quad \pm \\
3.69\end{array}$ & $\begin{array}{l}220.01 \\
2\end{array}$ & $<0.001^{* *}$ \\
\hline
\end{tabular}

ADMA: Asymmetric dimethylarginine; IMT: intima-media thickness FMD = flow mediated dilatation

Table 2: Comparison of ADMA, IMT and FMD in studied groups.

\begin{tabular}{|l|l|l|l|l|}
\hline \multirow{2}{*}{$\begin{array}{l}\text { Proup } \\
\text { Parameter }\end{array}$} & $\begin{array}{l}\text { Group 1 } \\
\text { CRF }\end{array}$ & $\begin{array}{l}\text { Group 2 } \\
\text { CKD }\end{array}$ & $\begin{array}{l}\text { Group 3 } \\
\text { Control }\end{array}$ & P-value \\
\cline { 2 - 5 } & \multicolumn{3}{|c|}{ Mean \pm SD } \\
\hline Creatinine (mg/dl) & $8.96 \pm 4.05$ & $4.16 \pm 0.45$ & $0.69 \pm 0.19$ & $<0.001^{* *}$ \\
\hline Hgb (gm/dl) & $10.62 \pm 1.99$ & $9.21 \pm 0.87$ & $14.10 \pm 1.24$ & $<0.001^{* *}$ \\
\hline Albumin (gm/dl) & $3.90 \pm 0.60$ & $3.14 \pm 0.43$ & $4.44 \pm 0.60$ & $<0.001^{* *}$ \\
\hline Cholesterol (mg/dl) & $164.1 \pm 43.1$ & $228.7 \pm 66.6$ & $124.2 \pm 31.4$ & $<0.001^{* *}$ \\
\hline TG (mg/dl) & $196.5 \pm 143.1$ & $153.1 \pm 90.6$ & $93.8 \pm 21.9$ & $0.001^{* *}$ \\
\hline
\end{tabular}

Table 3: Laboratory investigation among studied groups.

\begin{tabular}{|l|l|l|}
\hline Variables & $\mathbf{r}$ & P-value \\
\hline Creatinine $(\mathrm{mg} / \mathrm{dl})$ & 0.547 & $<0.001^{* *}$ \\
\hline IMT $(\mathrm{mm})$ & 0.552 & $<0.001^{* *}$ \\
\hline FMD\% & $0.625-$ & $<0.001^{* *}$ \\
\hline Age $(\mathrm{yrs})$ & -0.133 & $>0.05$ \\
\hline Hemoglobin $(\mathrm{gm} / \mathrm{dl})$ & -0.510 & $<0.001^{* *}$ \\
\hline Albumin $(\mathrm{gm} / \mathrm{dl})$ & -0.209 & $<0.05$ \\
\hline Cholesterol $(\mathrm{mg} / \mathrm{dl})$ & 0.214 & $<0.05$ \\
\hline Triglycride $(\mathrm{mg} / \mathrm{dl})$ & 0.322 & $0.001^{* *}$ \\
\hline Body weight(Kg) & -0.123 & $>0.05$ \\
\hline GFR & -0.296 & $>0.05$ \\
\hline
\end{tabular}

Table 4: Correlation between ADMA and different variables.

There was a statistical significant positive correlation between ADMA and creatinine, IMT, cholesterol, triglycride. However there was a statistical significant negative correlation between ADMA and FMD, hemoglobin, albumin (Table 4).

\section{Cut off value}

24.73

\begin{tabular}{|l|l|}
\hline Sensitivity & $98 \%$ \\
\hline Specificity & $58 \%$ \\
\hline Area under the curve (AUC) & 0.820 \\
\hline Standard error & 0.042 \\
\hline 95\% Confidence interval & $0.739-0.902$ \\
\hline Significance level (P-value) & $<0.001^{\text {** }}$ \\
\hline
\end{tabular}

Table 5: Validity of ADMA in diagnosis of CRF.

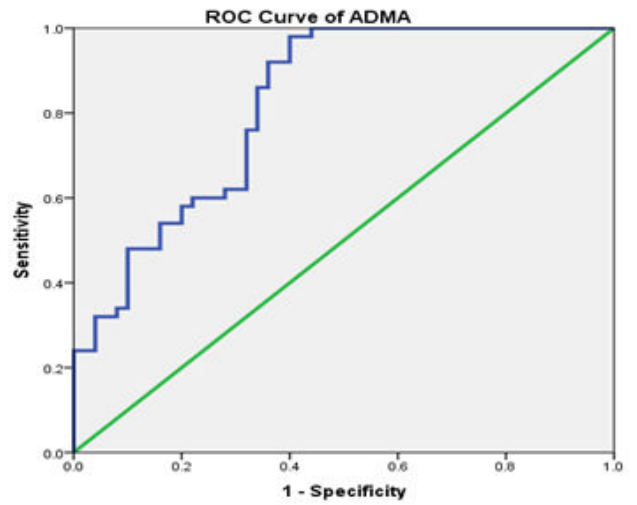

Figure 1: Receiver operating curve analysis of ADMA, (AUC) = 0.820 . Best cutoff value of ADMA was 24.73 with sensitivity $98 \%$, specificity $58 \%$.

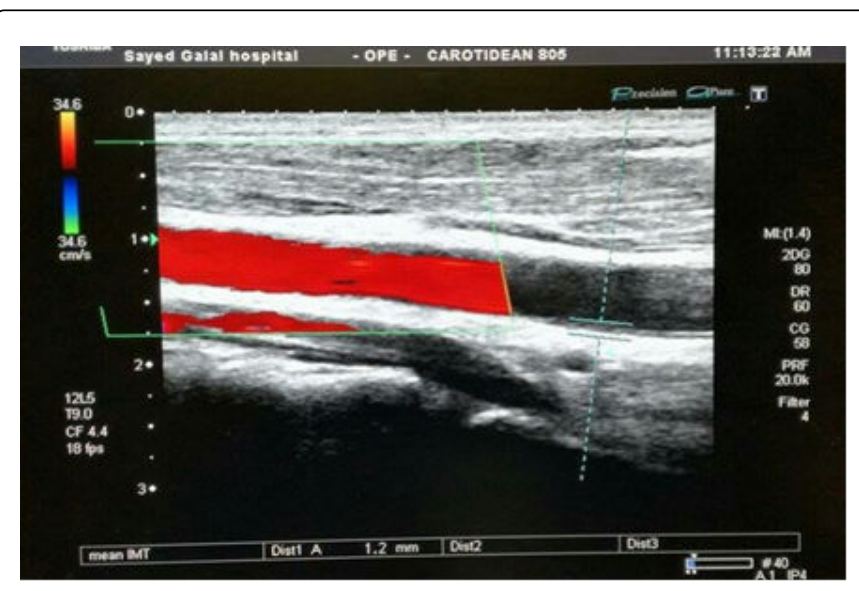

Figure 2: Measurement of IMT using Doppler US in a hemodialysis patient. IMT thickness $=1.2 \mathrm{~mm}$. The increased IMT was directly linked to high levels of serum ADMA which was responsible for increased morbidity and mortality in these patients.

Best cutoff value of ADMA was 24.73 with sensitivity 98\%, specificity $58 \%$. So ADMA value was significant in diagnosis of CRF as area under curve (AUC) was 0.820 , and p-value $<0.001$ (Table 5 and Figures 1 and 2). 


\section{Discussion}

Results in this study confirmed that serum ADMA levels were significantly higher in hemodialysis patients and in CKD stage 4 patients than in control group. This could be due to higher levels of protein methylation, increased rate of protein turnover, decreased excretion and decreased activity of DDAH enzymes that is effective in catabolism of ADMA [3].

Results obtained in this study went in agreement with the results reported by Böger and Schwedhelm [4] and Vatansev et al. [3] who found that plasma ADMA levels were significantly increased in patients undergoing $\mathrm{HD}$, suggesting that there was pathophysiological role of ADMA in these patients with cardiovascular diseases.

In the current study, serum albumin level of dialysis patients and CKD stage 4 patients was significantly lower as compared to healthy control group which could be explained by the interrelationship between hypoalbuminemia, inflammation, malnutrition and atherosclerosis due to appetite suppression and increased catabolism by inflammatory cytokines. Also, hypoalbuminemia lead to decreased antioxidant capacity [15]. Kalantar-Zadeh et al. [16] showed an association between serum albumin level and CVD in hemodialysis patients and stated that hypoalbuminemia could be a strong predictor of mortality in dialysis patients.

Similar results were obtained by Joki et al. [17] who demonstrated that patients in predialysis chronic renal failure with carotid plaque had lower serum albumin level and that hypoalbuminemia was an excellent reflection of cardiovascular diseases.

This study revealed that FMD values in brachial artery were significantly lower in hemodialysis patients and CKD stage 4 patients in comparison to that in controls. Our results could be explained by the fact that endothelial dysfunction is considered to be a systemic issue. Albuminuria leads to a reduction in the endothelium-dependent vascular relaxation response in glomerular endothelial cells [18]. Potential mediators between kidney function and endothelial function included ADMA and TNF- a [19]. Similar results were found by Recio-Mayoral et al. [20] and Shukla et al. [21] who observed that hemodialysis and CKD stage 4patients had reduced FMD values as compared to controls. Chong et al. [19] found an inverse relationship between renal function and FMD in symptomatic peripheral arterial disease.

In the current study, there was an inverse relationship between serum ADMA and endothelial function as measured by FMD. Probably, the chronic inflammation documented in these patients may be considered the mechanistic link between ADMA and vascular damage. Similar results were obtained by Yilmaz et al. [22] who stated an inverse relationship between serum ADMA and FMD.

Also, this study revealed that levels of serum cholesterol as well as triglycrides levels were significantly higher in hemodialysis patients and CKD stage 4 patients as compared to that in controls. Serum triglycerides elevated in CRF because of dysfunction of TG degradation resulted from insufficient mitochondrial beta-oxidation of fatty acids. Hyperinsulinemia was the main factor increasing synthesis of TG and decreasing the activity of lipoprotein lipase [23,24]. Our results went in agreement with the results obtained by Chong et al. [3] and Shukla et al. [21] who stated that chronic renal failure patients suffered from dyslipidemia that was associated with endothelial dysfunction.
Our study revealed that there was a statistical significant positive correlation between ADMA, creatinine, CIMT, cholesterol and triglycerides. However, there was a statistical significant negative correlation between ADMA and FMD, hemoglobin and albumin. Also, the significant positive correlation between ADMA, cholesterol and triglycerides could be explained by the fact that elevated levels of oxidized LDLs lead to a reduction in DDAH activity thus increased ADMA levels [8]. Riccioni et al. [8] stated that total cholesterol, triglycerides plasma concentrations and high serum ADMA levels were significantly associated with asymptomatic carotid atherosclerosis as measured by CIMT.

\section{Conclusion}

In the present study, there was a positive correlation between ADMA and carotid intima-media thickness (CIMT) which could be attributed to endothelial dysfunction resulted from increased ADMA levels and other traditional risk factors of atherosclerosis. These results went in agreement with the results obtained by Riccioni et al. [8] who stated that high serum concentrations of ADMA were associated with carotid atherosclerotic lesions as measured by CIMT and may represent a new marker of asymptomatic carotid atherosclerosis.

Hafner et al. [25] found that there was elevated levels of ADMA, decreased flow mediated dilatation, enlarged intima-media thickness in symptomatic peripheral arterial disease that was linked to increased cardio-vascular risk. Also Janda et al. [26] confirmed that in chronic renal failure and in CKD stage 4 patients, Radial artery calcifications and intimal atherosclerotic changes frequently coexist and this was significant predictor of mortality, independent of dialysis status.

\section{Conflict of Interest}

The authors declare no conflict of interest.

\section{References}

1. Franceschelli S, Ferrone A, Pesce M, Riccioni G, Speranza L (2013) Biological functional relevance of asymmetric dimethylarginine (ADMA) in cardiovascular disease. Int J Mol Sci 14: 24412-24421.

2. Serg M, Kampus P, Kals J, Zagura M, Muda P, et al. (2011) Association between asymmetric dimethylarginine and indices of vascular function in patients with essential hypertension. Blood Press 20: 111-116.

3. Ugurcu V, Vatansev H, Unlu A, Sivrikaya A, Akyurek F, et al. (2014) Levels of arginine and its products in dialysis patients. Eur Rev Med Pharmacol Sci 18: 2357-2364.

4. Schwedhelm E, Böger RH (2011) The role of asymmetric and symmetric dimethylarginines in renal disease. Nat Rev Nephrol 7: 275-285.

5. Fujii H, Takiuchi S, Kawano Y, Fukagawa M (2008) Putative role of asymmetric dimethylarginine in microvascular disease of kidney and heart in hypertensive patients. Am J Hypertens 21: 650-656.

6. Xia W, Feng W, Guan M, Yu Y, Li J, et al. (2010) Increased levels of asymmetric dimethylarginine and C-reactive protein are associated with impaired vascular reactivity in essential hypertension. Clin Exp Hypertens 32: 43-48.

7. Vladimirova-Kitova L, Deneva T, Angelova E, Nikolov F, Marinov B, et al. (2008) Relationship of asymmetric dimethylarginine with flow-mediated dilatation in subjects with newly detected severe hypercholesterolemia. Clin Physiol Funct Imaging 28: 417-425.

8. Riccioni G, Scotti L, D’Orazio N, Gallina S, Speziale G, et al. (2014) ADMA/SDMA in elderly subjects with asymptomatic carotid atherosclerosis: Values and site-specific association. Int J Mol Sci 15: 6391-6398. 
Citation: Rashed A, Soliman K, Aun A, Ezzat H (2017) Relationship Between Asymmetric Dimethylarginine (ADMA) and Atherosclerosis in Chronic Renal Failure Patients. J Nephrol Ther 7: 300. doi:10.4172/2161-0959.1000300

Page 5 of 5

9. Sibal L, Agarwal SC, Home PD, Boger RH (2010) The role of asymmetric dimethylarginine (ADMA) in endothelial dysfunction and cardiovascular disease. Curr Cardiol Rev 6: 82-90.

10. Cibulka R, Racek J (2007) Metabolic disorders in patients with chronic kidney failure. Physiol Res 56: 697-705.

11. Cockcroft DW, Gault MH (1976) Prediction of creatinine clearance from serum creatinine. Nephron 16: 31-41.

12. Bouras G, Deftereos S, Tousoulis D, Giannopoulos G, Chatzis G, et al. (2013) Asymmetric Dimethylarginine (ADMA): A promising biomarker for cardiovascular disease? Curr Top Med Chem 13: 180-200.

13. Corretti MC, Anderson TJ, Benjamin EJ, Celermajer D, Charbonneau F et al. (2002) Guidelines for the ultrasound assessment of endothelialdependent flow-mediated vasodilation of the brachial artery: A report of the Inter-national Brachial Artery Reactivity Task Force. J Am Coll Cardiol 39: 257-265.

14. IBM Corp Released (2013) IBM SPSS Statistics for Windows, Version 22.0. Armonk. IBM Corp, New York.

15. Kalantar-Zadeh K, Kopple JD, Block G, Humphreys MH (2001) A malnutrition-inflammation score is correlated with morbidity and mortality in maint-enance hemodialysis patients. Am J Kidney Dis 38: 1251-1263.

16. Kalantar-Zadeh K, Kilpatrick RD, Kuwae N, McAllister CJ, Alcorn H, et al. (2005) Revisiting mortality predictability of serum albumin in the dialysis population: Time dependency, longitudinal changes and population-attributable fraction. Nephrol Dial Transplant 20: 1880-1888.

17. Joki N, Hase H, Tanaka Y, Takahashi Y, Saijyo T, et al. (2006) Relationship between serum albumin level before initiating haemodialysis and angiographic severity of coronary atherosclerosis in end-stage renal disease. Nephrol Dial Transplant 21: 1633-1639.

18. Satoh M (2012) Endothelial dysfunction as an underlying pathophysiological condition of chronic kidney disease. Clin Exp Nephrol 16: 518-521.
19. Chong KC, Owens CD, Park M, Alley HF, Boscardin WJ, et al. (2014) Relationship between kidney disease and endothelial function in peripheral artery disease. J Vasc Surg 60: 1605-1611.

20. Recio-Mayoral A, Banerjee D, Streather C, Kaski JC (2011) Endothelial dysfunction, inflammation and atherosclerosis in chronic kidney disease: a cross-sectional study of predialysis, dialysis and kidney transplantation patients. Atherosclerosis 216: 446-451.

21. Shukla V, Dey R, Chandra A, Karoli R, Khanduri S (2015) Endothelial dysfunction by flow-mediated vasodilatation in chronic kidney disease. J Assoc Physicians India 63: 30-33.

22. Yilmaz MI, Sonmez A, Saglam M, Qureshi AR, Carrero JJ, et al. (2008) ADMA levels correlate with proteinuria, secondary amyloidosis and endothelial dysfunction. J Am Soc Nephrol 19: 388-395.

23. Cibulka R, Racek J, Vesela E (2005) The importance of L-carnitine in patients with chronic renal failure treated with hemodialysis (in Czech). V Nitr Lek 51: 1108-1113.

24. Feng M, Liu L, Guo Z, Xiong Y (2008) Gene transfer of dimethylarginine dimethylaminohydrolase-2 improves the impairments of DDAH/ ADMA/NOS/NO pathway in endothelial cells induced by lysophosphatidylcholine. Eur J Pharmacol 584: 49-56.

25. Hafner F, Kieninger A, Meinitzer A, Gary T, Froehlich H, et al. (2014) Endothelial dysfunction and brachial intima-media thickness: Long term cardiovascular risk with claudication related to peripheral arterial disease: A prospective analysis. PLoS One 9: 933-957.

26. Janda K, Krzanowski M, Gajda M, Dumnicka P, Fedak D, et al. (2015) Cardiovascular risk in chronic kidney disease patients: intima-media thickness predicts the incidence and severity of histologically assessed medial calcification in radial arteries. BMC Nephrol 16: 78. 